\title{
Acute toxicity of peroxy sulfonated oleic acids (PSOA) to freshwater aquatic species and sludge microflora as observed in laboratory environments
}

\author{
Stephan Solloch ${ }^{1 *}$, Nathan Pechacek ${ }^{2}$, Bridget Peterson ${ }^{2}$, Magdalena Osorio² and Jeffrey Caudill ${ }^{3}$
}

\begin{abstract}
Background: Peroxy sulfonated oleic acids (PSOA) is a novel surfactant peracid. The commercialapplications of PSOA result in the chemical primarily being disposed of via industrial waste water effluent.Given this manner of disposal, it is important to understand the aquatic hazards of the chemical to betterassess the risk posed to aqueous environments. Acute aquatic toxicity laboratory experiments wereperformed to evaluate aquatic hazards and were conducted according to standard OECD test guidelineswith rainbow trout (Oncorhynchus mykiss), water fleas (Daphnia magna) and algae (Pseudokirchneriellasubcapitata). In addition, microbial toxicity was evaluated in activated sludge obtained from a domesticsewage treatment facility.

Results: Lethal concentration in $50 \%$ of test species $\left(\mathrm{LC}_{50}\right)$ and effect concentration in $50 \%$ of test species $\left(\mathrm{EC}_{50}\right)$ values for PSOA ranged from 0.75 to $5.44 \mathrm{mg} / \mathrm{L}$, representing a relatively small range spanning less than an order of magnitude. No observed effect concentration (NOEC) and lowest observed effect concentration (LOEC) ranges were also relatively small, with ranges of $0.25-1.66$ and $0.5-3.6 \mathrm{mg} / \mathrm{L}$, respectively. The $E_{50}$, $L O E C$ and NOEC values for microbial toxicity were 216,60 and $20 \mathrm{mg} / \mathrm{L}$, respectively. Predicted no effect concentrations (PNEC) for aqueous media were based on the $96-\mathrm{h} \mathrm{LC} \mathrm{C}_{50}(0.75 \mathrm{mg} / \mathrm{L})$ for 0 . mykiss, the organism displaying the greatest sensitivity to PSOA. These values were derived for freshwater, marine water and intermittent releases to water and ranged from $7.5 \times 10^{-5}$ to $7.5 \times 10^{-3} \mathrm{mg} / \mathrm{L}$. A sewage treatment plant PNEC of $2 \mathrm{mg} / \mathrm{L}$ was derived based on an activated sludge 3-h NOEC of $20 \mathrm{mg} / \mathrm{L}$.
\end{abstract}

Conclusion: These values, along with the anticipated environmental fate and transport for PSOA, were considered in assessing the overall aquatic risk posed by this chemical. Despite the relatively high acute aquatic hazards for PSOA, environmental modeling suggests the overall risk of PSOA to aqueous environments is low based on its anticipated uses. This conclusion is consistent with the significant processing of industrial wastewater by onsite or municipal wastewater treatment facilities prior to release to the environment.

Keywords: Laboratory aquatic study, Acute aquatic toxicity, Peroxy sulfonated oleic acids (PSOA), PNEC, Oncorhynchus mykiss, Daphnia magna, Pseudokirchneriella subcapitata

\section{Background}

Peroxy sulfonated oleic acids (PSOA) is the common name of the substance "reaction product of sulfonated oleic acid potassium salt, hydrogen peroxide and sulfuric

*Correspondence: stephansolloch@web.de

1 Ecolab, Monheim, Germany

Full list of author information is available at the end of the article acid" (IUPAC name) (see Fig. 1). The official CAS entry is "9-Octadecanoic acid (9Z)-, sufonated, oxidized, potassium salts" (CAS number 1315321-94-8). As described in Pechacek et al. [13], PSOA is an organic peroxide that is characterized by the presence of one or more oxygenoxygen bonds and is derived by reacting sulfonated oleic acid and hydrogen peroxide under acidic conditions 


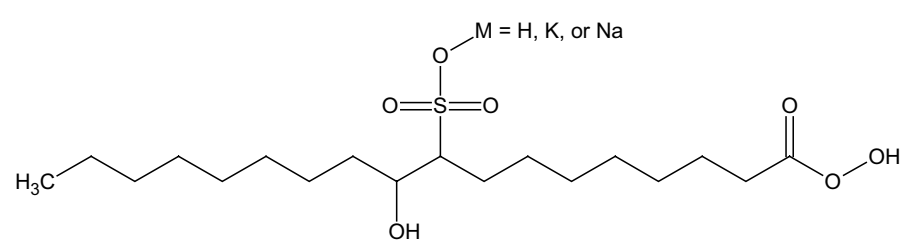

Fig. 1 Chemical structure of PSOA

$[13,14]$. The oleic acid used in the production of PSOA is derived from renewable feedstocks such as plant oils and animal tallow [13]. Due to the variability inherent in the natural feedstock used to obtain oleic acid, PSOA subsequently falls into the regulatory definition of an unknown or variable composition, complex reaction products or biological materials (UVCB) substance [5, 13]. The resulting equilibrium mixture contains peroxy sulfonated acids, hydrogen peroxide, water and residual acid.

PSOA is a novel surfactant peracid developed to alleviate challenges with current peracid technology. It is commercially used as an antimicrobial, bleaching or coupling agent. Food and beverage industries primarily use PSOA as a coupling agent to clean and sanitize processing equipment [13]. PSOA is commonly available commercially as a concentrate due to its ability to maintain equilibrium longer as a concentrate than in diluted solutions. When PSOA comes into contact with organic matter such as milk or blood, it rapidly decomposes to its precursor reactants. Additionally, it rapidly decomposes when dried on a surface due to the water loss that shifts the equilibrium of the PSOA mixture [7]. PSOA is readily soluble in water with an aqueous solubility of $\geq 43.8 \mathrm{~g} / \mathrm{L}$ at approximately $20^{\circ} \mathrm{C}$ [15]. However, it is hydrolytically unstable and significant hydrolysis occurs at environmentally relevant $\mathrm{pH}$ values $(4,7$ and 9$)$ [2].

Disposal of PSOA primarily occurs in industrial wastewater effluent. Given this method of disposal, it is important to characterize the aquatic hazards of PSOA. This publication summarizes the results of four studies: a 96-h continuous flow study with rainbow trout (Oncorhynchus mykiss), a 48-h immobilization test with Daphnia magna, a 72-h algal growth inhibition test with P. subcapitata and a 3-h respiration inhibition test (ASRIT) with activated sludge. Given the known environmental fate and transport of PSOA in aqueous environments, the overall goal is to discuss the aquatic hazards identified in their appropriate risk context.

\section{Methods}

\section{Test item}

100 \% UVCB substance PSOA was synthesized by Ecolab chemists and served as the test article. PSOA was stored at $-20{ }^{\circ} \mathrm{C}$ and thawed prior to preparation of stock solutions, and was described as a viscous, pasty white or yellowish liquid. The PSOA used in all described tests originated from the same manufactured batch.

\section{Experimental organisms}

To determine the aquatic toxicity of PSOA, acute toxicity experiments were performed on three different freshwater species: rainbow trout $(O . m y k i s s)$, water flea $(D$. magna) and algae (P. subcapitata). Acute lethality was evaluated for the fish $(96 \mathrm{~h})$, acute immobilization for the D. magna $(48 \mathrm{~h})$ and effects to growth rate and yield for algae (72 h). In addition, the toxicity of PSOA to indigenous microflora found in activated sludge of a domestic sewage treatment facility was assessed.

\section{Fish}

Fish obtained from Selcoth Fish Farm in Moffat, Scotland were used for the initial and repeat range finding tests, while fish from Brow Well Fisheries Ltd., Skipton, England were used in the definitive test. Fish measured $4-6 \mathrm{~cm}$ in length and were free from any apparent malformation or poor health. All fish were acclimated to laboratory conditions for a minimum of 12 days prior to commencement of the study. During holding, fish were fed daily. Twentyfour hours prior to initiation of the study, food was withheld from the fish and no food was provided during the study.

\section{Daphnia magna}

Daphnia were obtained from the Laboratory of Hydrobiology (Central Agricultural Office, Directorate of Plant and Soil Protection), Hungary. All daphnids were female and under $24 \mathrm{~h}$ old. Daphnia were bred and acclimatized in the laboratory under similar temperatures, light conditions and water quality as were used in the definitive test. Daphnia were fed a centrifuged green alga suspension during holding and no food was provided during the study.

\section{Algae}

Algae were supplied by the SAG: Collection of Algal Cultures, Institute of Plant Physiology, University of Göttingen, Germany. The stock cultures were small algal 
cultures that were planted on agar regularly and transferred to fresh medium at least once every 2 months. The pre-culture was intended to give an amount of algae suitable for the inoculation of test cultures. The pre-culture was prepared with Algal Mineral Salts Culture Medium, incubated under the conditions of the definitive test and used when growing exponentially, which normally occurred after an incubation period of 3 days.

\section{Activated sludge}

Activated sludge was obtained from Totnes Sewage Works, Totnes, Devon, UK 1 day prior to the start of the definitive test. This sludge was used predominantly in the treatment of domestic sewage. The activated sludge was settled and the supernatant decanted. The settled sludge was incubated with $50 \mathrm{~mL}$ of OECD synthetic sewage feed per liter of sludge per day and aerated at room temperature until testing commenced. The OECD synthetic sewage feed was prepared as described in OECD Test Guideline 209 [12].

\section{Aquaria and water quality \\ Fish}

Fish were kept in 12-L (initial and repeat range finding tests) and 17-L (definitive test) tanks of reconstituted freshwater (RFW) according to the formula recommended by OECD Guideline 203 [9]. High-grade salts were dissolved in $500 \mathrm{~L}$ of deionized, reverse osmosisgrade water and this solution was metered into a flow of deionized water to produce reconstituted water. Reconstituted water was stored at $12{ }^{\circ} \mathrm{C}$ and constantly aerated. For the initial range finding test, the $\mathrm{pH}$ of the holding and test medium was adjusted to 5.0-6.5. For the repeat range finding test and the definitive test, a reduced $\mathrm{pH}$ was not required and the holding and test medium were maintained at a $\mathrm{pH}$ range of $6.0-8.5$. Test vessels were kept within a temperature-controlled laboratory with the aim of achieving a temperature in the range of $13-17^{\circ} \mathrm{C}$. A light cycle of $16 \mathrm{~h}$ of light and $8 \mathrm{~h}$ of darkness was in operation throughout the test. Artificial daylight fluorescent tubes provided illumination.

\section{Daphnia magna}

Daphnia were kept in beakers containing approximately $40 \mathrm{~L}$ test medium. Reconstituted water (ISO medium according to OECD 202) was prepared by adding $25 \mathrm{~mL}$ from each of four stock solutions to $1 \mathrm{~L}$ of water [10]. It had an approximate total hardness of $249 \mathrm{mg} / \mathrm{L} \mathrm{CaCO}_{3}$, a dissolved oxygen concentration of $8.31-8.81 \mathrm{mg} / \mathrm{L}$, a $\mathrm{pH}$ of $7.50-8.08$ and a temperature range of $19.6-20.5^{\circ} \mathrm{C}$. The temperature of the climate chamber was in the range of $19.2-20.6{ }^{\circ} \mathrm{C}$, with 16 -h light and 8-h dark cycles. Artificial daylight fluorescent tubes provided illumination.

\section{Algae}

Algae were kept in 250-mL Erlenmeyer flasks with $100 \mathrm{~mL}$ test medium. Water temperature in the flasks was in the range of $22.4-23.0^{\circ} \mathrm{C}$ while the climate chamber had a temperature range of $22.1-23.9^{\circ} \mathrm{C}$. The $\mathrm{pH}$ was measured at the beginning and end of the study for each test concentration and the control, and it ranged from 5.99 to 8.57. Algal flasks were continuously illuminated. The light intensity at the position occupied by the algal cultures in the flasks was approximately 7947 lux, which was maintained by fluorescent lamps with a spectral range of $400-700 \mathrm{~nm}$. The light intensity between test flasks did not vary in excess of $\pm 15 \%$.

\section{Activated sludge}

The activated sludge contained a total filterable solid concentration of $8307 \mathrm{mg} / \mathrm{L}$ as determined on the day of testing. The $\mathrm{pH}$ of the sludge was measured as 5.5 and adjusted to 7.3 by the addition of $2 \mathrm{M}$ sodium hydroxide. One drop of antifoaming agent, antifoam B emulsion, was dispensed in each flask after initial foaming was observed during aeration. The antifoam B emulsion contained $10 \%$ active silicone. Flasks containing activated sludge were aerated at a temperature of $20 \pm 2{ }^{\circ} \mathrm{C}$.

\section{Experimental designs \\ Fish}

Preliminary range finding testing was conducted to determine the appropriate concentrations of the test item for the definitive testing. Weighed amounts of PSOA (5.01, $10.12,20.15$ and $50.3 \mathrm{mg}$ ) were individually added to $1 \mathrm{~L}$ of RFW and ultrasonicated for $30 \mathrm{~s}$ to ensure solubility and homogeneity to create four nominal concentrations: $5,10,20$ and $50 \mathrm{mg} / \mathrm{L}$. The $\mathrm{pH}$ values for each solution were determined. Based on these values, the initial range finding test was conducted at $20 \mathrm{mg} / \mathrm{L}$, as this test concentration had a $\mathrm{pH}$ (5.78) similar to the $\mathrm{pH}$ to which the fish were acclimating. The initial range finding test was conducted over a $96-\mathrm{h}$ period under semi-static conditions, at nominal concentrations of 2.5, 5, 10 and $20 \mathrm{mg} / \mathrm{L}$ with an untreated control. Three fish per tank were used, with one tank per concentration and one control. Due to overt effects observed within $18 \mathrm{~min}$ at all test concentrations, the study was terminated and all fish were humanely euthanized to avoid additional stress. A repeat range finding test was conducted at 0.002, 0.02, 0.2 and $2 \mathrm{mg} / \mathrm{L}$ with an untreated control. Once again, three fish per tank with one tank per concentration and control were used. Test solutions were prepared daily by dilution of a $20 \mathrm{mg}$ PSOA/L stock solution with RFW. Fish were transferred to freshly prepared test solutions at 24-h intervals.

The definitive 96-h test with fish was conducted at nominal PSOA concentrations of $0.0625,0.125,0.25$, 
0.5 and $1 \mathrm{mg} / \mathrm{L}$ with a solvent and untreated control and continuous flow conditions. Seven fish were randomly added to each tank at the start of the exposure phase. For determination of the PSOA concentration, samples were taken from the testing concentrations and the controls at $-24,0,24$ and $96 \mathrm{~h}$. For each test concentration, RFW was passed from a header tank into a pre-exposure glass mixing vessel containing a magnetic follower. The nominal flow rate of RFW to each mixing vessel was $35 \mathrm{~mL} /$ min which equated to five volume replacements per tank every $24 \mathrm{~h}$. The water was mixed with a continuous flow of stock solution of PSOA in acetone or acetone alone for the solvent control. The stock solutions were contained in Becton-Dickinson syringes equipped with a 16-gauge Teflon syringe infusion tube and delivered using Medfusion Syringe Infusion Pumps, Model 2001. Stock solutions at the appropriate concentration were delivered to the mixing vessel at a rate of $0.21 \mathrm{~mL} / \mathrm{h}$ where they were mixed with the dilution water. The test solutions flowed through tubing directly to the appropriate tank at a continuously controlled flow rate. Excess solution was siphoned off with an overflow tube. The delivery of solutions to the solvent and non-solvent control tanks was identical to the treated tanks but excluded PSOA. The solvent control received acetone only from the infusion pump, which was mixed with RFW and the non-solvent control received only RFW. Dose solution delivery rates were confirmed daily for each tank by collecting the outflow of dose solution over a timed interval and measuring the volume. Temperature, $\mathrm{pH}$, conductivity, dissolved oxygen concentration and hardness of test water were also monitored throughout the study. During the in-life phase of the test, fish were observed at 1, 4, 24, 48, 72 and $96 \mathrm{~h}$. Incidence of fish death was recorded and abnormalities noted. At the conclusion of the study, the length and weight of surviving fish were recorded.

\section{Daphnia magna}

For the range finding test for Daphnia, nominal PSOA concentrations of $0.01,0.1,1,10$ and $100 \mathrm{mg} / \mathrm{L}$ were prepared by appropriate dilution of a stock PSOA solution. The stock solution consisted of $100 \mathrm{mg}$ PSOA/L and was prepared by dispersing the test item in ISO medium and then shaking for $30 \mathrm{~min}$. Non-dissolved test material was separated by centrifugation. For the range finding test, ten daphnids for each test concentration and control were exposed for $48 \mathrm{~h}$. Two replications of this test were conducted.

Based on the observations for the range finding test, five test concentrations in a geometric series with a separation factor of two and one control was used in the 48-h definitive test. The nominal concentrations were $0,2.5$, 5.0, 10.0, 20.0 and $40.0 \mathrm{mg} / \mathrm{L}$. Preparation of the stock PSOA solution and test solutions occurred in the same manner as the range finding test. For determination of the PSOA concentration, samples were taken from the testing concentrations and the control at the start and end of each water renewal period. A semi-static water renewal method was chosen with a renewal frequency period of $24 \mathrm{~h}$. Twenty Daphnia were exposed to each test concentration, with the twenty animals divided into four groups of five. Each group resided in approximately $40 \mathrm{~mL}$ of test medium. Daphnia were observed at 24and 48-h intervals and were considered immobile when they were unable to swim after $15 \mathrm{~s}$.

\section{Algae}

A range finding test was conducted in which algae were exposed for $72 \mathrm{~h}$ to nominal concentrations of $0.01,0.1$, 1,10 and $100 \mathrm{mg} / \mathrm{L}$. A PSOA stock solution and test solutions were prepared for the range finding and definitive tests as described in "Daphnia magna" section. Based on cell number counts from the range finding study, six test concentrations in a geometric series with a separation factor of two and one control was used in the 72-h definitive test. The nominal concentrations were $0,0.4$, 1.0, 2.6, 6.4, 16.0 and $40.0 \mathrm{mg} / \mathrm{L}$. Introduction of algae into the $250-\mathrm{mL}$ Erlenmeyer flasks occurred at $0 \mathrm{~h}$ by inoculation of $0.1 \mathrm{~mL}$ algal biomass $\left(10^{7}\right.$ algal cells $\left./ \mathrm{mL}\right)$ into $100 \mathrm{~mL}$ test solutions. The algal cells were taken from an exponentially growing pre-culture established 4 days prior to the start of the definitive study. The initial cell density was about $10^{4}$ cells $/ \mathrm{mL}$ in each test flask. There were three replicates per test concentration and six replicates in the untreated control. During incubation the flasks were stored on an orbital shaker and continuously shaken. Algal cell numbers and morphology were assessed at 24, 48 and $72 \mathrm{~h}$. Cell number was determined by manual cell counting using a microscope with a counting chamber. Morphology was assessed microscopically.

\section{Activated sludge}

The definitive study ran in two sets of 3-h exposure periods in the course of 1 day. The first set consisted of three PSOA concentrations, five reference flasks and four control flasks. The second set consisted of two PSOA concentrations, five reference flasks and three control flasks. Nominal concentrations of 6, 20,60, 200 and $600 \mathrm{mg}$ $\mathrm{PSOA} / \mathrm{L}$ were prepared in replicates of five, in addition to a control. Flasks of the reference substance, 3,5-dichlorophenol $(3,5-\mathrm{DCP})$ were prepared at nominal concentrations of 3.2, 10, 32 and $100 \mathrm{mg} / \mathrm{L}$. 3,5-DCP was used as a reference substance given its known inhibitory effect on respiration, as well to ensure that the batch of sludge used in the test showed a representative level of sensitivity. An abiotic flask at $100 \mathrm{mg} / \mathrm{L}$ and a control were also prepared. 
Each flask contained $3.2 \mathrm{~mL}$ of synthetic sewage and $18 \mathrm{~mL}$ of activated sludge to give a final solids concentration of $1500 \mathrm{mg} / \mathrm{L}$ (with the exception of the abiotic flask), an appropriate quantity of either PSOA or 3,5DCP stock solution and reverse osmosis water to give a final flask contents volume of $100 \mathrm{~mL}$. After foaming was observed in the first aerating flasks, one drop of antifoaming agent was added to each test flask. The $\mathrm{pH}$ of each flask was measured at the beginning and end of the test. The $\mathrm{pH}$ of the PSOA stock solution was adjusted to 6.6 before use and the reference substance stock solution had a $\mathrm{pH}$ of 7.3.

Flasks were established in batches of six and aerated at $20 \pm 2{ }^{\circ} \mathrm{C}$ for $3 \mathrm{~h}$. Each batch included a control flask and five test or reference substance flasks. The temperatures of the flask contents were measured at the end of the $3 \mathrm{~h}$ aeration using a mercury-in-glass thermometer. The respiration rate of each flask was measured after $3 \mathrm{~h}$ and compared with the mean respiration rates of the control flasks. The rate of oxygen uptake was measured in glass sample tubes into which microcathode oxygen electrodes were inserted. The electrodes were connected to an interface unit, which converted the current produced by the electrodes into dissolved oxygen readings. These readings were transferred to a computer that calculated the respiration rate in each flask over the linear part of the curve and compared it to the mean of the control cultures. The rates of oxygen uptake were expressed as $\mathrm{mg} / \mathrm{L} / \mathrm{h}$.

\section{Analytical measurements}

\section{Fish}

An analytical procedure for the determination of PSOA in Tap Water formulations has been developed and validated by Charles River [3]. Formulation prepared at $2.5 \mu \mathrm{g} / \mathrm{mL}$ was found to be not stable when stored at ambient laboratory temperature in the dark. Formulation prepared at $150 \mu \mathrm{g} / \mathrm{mL}$ was found to be stable for $12 \mathrm{~h}$ when stored at ambient laboratory temperature in the dark. Due to the instability of the PSOA formulations in Tap Water the stability of PSOA in acetone was investigated. The formulation and analytical procedures were found to be satisfactory for a formulation prepared at $1.00 \mathrm{mg} / \mathrm{mL}$ in acetone which could be used for a flow through test in the ecotoxicology study.

In the range finding tests, analytical samples were collected in duplicate from the test concentrations at -24 , 0,24 and $96 \mathrm{~h}$ to assess stability. For the definitive test, duplicate samples were collected at the start of the study and after $72 \mathrm{~h}$. Samples were collected from expired test media after 24 and $96 \mathrm{~h}$. Sample analysis generally occurred on the same day as sampling. In cases where this was not feasible, the samples were stored under suitable conditions until analysis could take place.

\section{Daphnia magna}

Analytical samples were collected from the test concentrations and the control at the start and at the end of each water renewal period. Samples were analyzed directly using a photometric method in a manner similar to the fish study.

\section{Algae}

Analytical samples were collected from the test concentrations and the control at the start of the test and 24-h intervals thereafter. For these daily measurements, one extra replicate was used in each test concentration that was treated the same as the replicates used for determination of the algal cells. In a manner similar to the fish and Daphnia studies, samples were analyzed directly after sampling using a validated photometric method.

\section{Activated sludge}

No analytical measurements were taken during the study. Only nominal concentrations were used.

\section{Computational and statistical analysis \\ Fish}

Median lethal concentrations $\left(\mathrm{LC}_{50}\right)$ values were estimated by taking the arithmetic mean of the 0 and $100 \%$ mortality concentrations. No observed effect concentration (NOEC) values were based on both mortality and observed effects.

\section{Daphnia magna}

NOEC, lowest observed effect concentration (LOEC) and effective concentrations for the 50th and 100th percentile values $\left(\mathrm{EC}_{50}\right.$ and $\left.\mathrm{EC}_{100}\right)$ were determined for the definitive test. NOEC, LOEC and $\mathrm{EC}_{100}$ were identified directly from the data, while $\mathrm{EC}_{50}$ values were calculated by probit analysis with $95 \%$ confidence limits.

\section{Algae}

The inhibition of algal growth was determined from the average specific growth rate and yield using the following equations:

Average specific growth rate $(\mu): \mu_{i-j}$

$$
=\frac{\ln X_{j}-\ln X_{i}}{t_{j}-t_{i}}+\left(\text { day }^{-1}\right)
$$

where $\mu_{i-j}$ is average specific growth rate from time $i$ to $j$; $X_{j}$ is biomass at time $j ; X_{i}$ is biomass at time $i$.

Percent inhibition of growth rate $\left(\% I_{r}\right): \% I_{r}$

$$
=\frac{\mu_{C}-\mu_{T}}{\mu_{c}} \times 100
$$


where $\mu_{C}$ is mean value for average specific growth rate in the control group; $\mu_{T}$ is average specific growth rate for the treatment replicate.

$$
\begin{aligned}
& \text { Percent inhibition in yield }\left(\% I_{y}\right): \% I_{y} \\
& \quad=\frac{Y_{C}-Y_{T}}{Y_{C}} \times 100
\end{aligned}
$$

where $Y_{C}$ is mean value for yield in the control group; $Y_{T}$ is value for yield for the treatment group.

Mean values and standard deviations of cell concentrations were calculated for each treatment at $0,24,48$ and $72 \mathrm{~h}$. The percent inhibition of growth rate $(\mu)$ and yield $(y)$ was also calculated using Excel for Windows software. The $\mathrm{EC}_{50}$ values for growth rate and yield and their associated confidence limits were calculated using probit analysis based on measured geometric mean concentrations. For the determination of NOEC and LOEC, the calculated mean growth rate and yield at the test concentrations were tested on significant differences to the control values by Bonferroni $t$ test. TOXSTAT software was used to evaluate the normal distribution of the rate and its homoscedasticity. Using $\mathrm{EC}_{50}$, NOEC and LOEC values were identified for algal growth rate and yield.

\section{Activated sludge}

The respiration of the flasks dosed with the PSOA or 3,5DCP were expressed as percentages of the respiration rate of the control flasks and were derived as follows:

$$
\begin{aligned}
& \text { Percent inhibition : \% I } \\
& \quad=\left[1-\left[\frac{\text { Respiration rate of test flask }}{\text { Mean respiration rate of control flasks }}\right]\right] \times 100
\end{aligned}
$$

The effective concentrations (EC) for the 20th, 50th and 80th percentiles, as well as the NOEC for respiration inhibition, along with their 95th confidence intervals, were calculated by linear interpolation using the US EPA program ICPIN (Version 2, June 1993).

\section{Results \\ Range finding tests \\ Fish}

In the repeat range finding test, all fish in the highest dose group ( $2 \mathrm{mg} / \mathrm{L}$ ) experienced difficulties in respiration within $1 \mathrm{~h}$. Therefore, all fish were removed and humanely euthanized to avoid additional stress. Fish at all other test concentrations $(0.002,0.02$ and $0.2 \mathrm{mg} / \mathrm{L})$ appeared active and healthy throughout the exposure period with no abnormal effects or behavior. Measurement of all test solution quality parameters verified that $\mathrm{pH}$, temperature, conductivity and dissolved oxygen concentration remained within acceptable limits throughout the duration of the test: $\mathrm{pH}$ range of 6.52-6.94, temperature range of $14-16.8{ }^{\circ} \mathrm{C}$, conductivity range of $180.3-208 \mu \mathrm{S} / \mathrm{cm}$ and dissolved oxygen concentration range of $95-100 \%$ air saturation value.

\section{Daphnia magna}

In the preliminary range finding test the Daphnia were considered immobile if they were unable to swim after $15 \mathrm{~s}$. There were no immobile Daphnia observed at $48 \mathrm{~h}$ in the $0.01,0.1$ and $1 \mathrm{mg} / \mathrm{L}$ test groups. Six out of ten Daphnia were considered immobile in the $10 \mathrm{mg} / \mathrm{L}$ test group and all ten Daphnia were considered immobile in the $100 \mathrm{mg} / \mathrm{L}$ test group.

\section{Algae}

In the preliminary range finding test for algae, the nominal concentrations used were untreated, 0.01, $0.1,1,10$ and $100 \mathrm{mg} / \mathrm{L}$. The average of cell numbers at $72 \mathrm{~h}\left(\times 10^{4}\right.$ cells $\left./ \mathrm{mL}\right)$ was $67,65,61.5,59,43$ and 1.2 , respectively.

\section{Definitive tests \\ Fish}

The definitive test results for fish are based on nominal concentrations of PSOA given that the test sample analysis confirmed PSOA levels were maintained at 99-100\% of nominal concentrations over the study duration. One dead fish was removed after $21 \mathrm{~h}$ of exposure to the highest dose $(1 \mathrm{mg} / \mathrm{L})$. The remaining fish in the same tank appeared lethargic. Two more dead fish were removed after 22.75 and $24 \mathrm{~h}$, respectively. By $50.75 \mathrm{~h}$, the remaining four fish were dead. After $72 \mathrm{~h}$ at the second highest dose $(0.5 \mathrm{mg} / \mathrm{L})$, all fish appeared to be respiring at an increased rate. All fish in both controls and at $0.0625,0.125$ and $0.25 \mathrm{mg} / \mathrm{L}$ appeared active and healthy throughout the test period. Fish surviving to $96 \mathrm{~h}$ were within the range 4.02-5.23 cm in length and 0.6984$1.7030 \mathrm{~g}$ in dry weight. No concentration-dependent growth effects were observed. Measurement of all test solution quality parameters verified that $\mathrm{pH}$, temperature, conductivity and dissolved oxygen concentration remained within acceptable limits throughout the duration of the test: $\mathrm{pH}$ range of 6.41-7.15, temperature range of $16.0-16.9^{\circ} \mathrm{C}$, conductivity range of $194.8-208 \mu \mathrm{S} / \mathrm{cm}$ and dissolved oxygen concentration range of $74-97 \%$ air saturation value.

\section{Daphnia magna}

The nominal concentrations used to test Daphnia were $0,2.5,5.0,10.0,20.0$ and $40.0 \mathrm{mg} / \mathrm{L}$ with corresponding measured geometric mean concentrations of $0,1.28,2.69$, 6.89, 15.61 and $32.91 \mathrm{mg} / \mathrm{L}$, respectively. One hundred percent $(100 \%)$ of the daphnids were immobilized at 24 and $48 \mathrm{~h}$ at the two highest test concentrations (i.e., 15.61 
and $32.91 \mathrm{mg} / \mathrm{L})$. At $6.89 \mathrm{mg} / \mathrm{L}, 90 \%$ of the daphnids were immobilized at $24 \mathrm{~h}$ and $100 \%$ were immobilized at $48 \mathrm{~h}$. At $2.69 \mathrm{mg} / \mathrm{L}$, no immobilization was observed at $24 \mathrm{~h}$; however, $33 \%$ of the daphnids displayed immobilization at $48 \mathrm{~h}$. No immobilization was observed at $1.28 \mathrm{mg} / \mathrm{L}$ or the control for the 24- and 48-h observations.

\section{Algae}

The nominal concentrations used to test algae were 0.4 , 1.0, 2.6, 6.4, 16.0 and $40 \mathrm{mg} / \mathrm{L}$. Geometric mean exposure concentrations were calculated for all nominal test concentrations except for the lowest two (i.e., 0.4 and $1.0 \mathrm{mg} / \mathrm{L}$ ). The lowest two test concentrations were not within the measurable range of the photometric analytical method for the entire duration of the study and were not included in estimating $\mathrm{EC}_{50}$ values. For the third lowest test concentration, $2.6 \mathrm{mg} / \mathrm{L}$, one measured concentration was below the limit of quantification (LOQ) of $0.25 \mathrm{mg} / \mathrm{L}$ and was assigned a value of one-half the LOQ $(0.5 \times$ LOQ $)$ in calculating the geometric mean concentration. For the nominal concentrations of 2.6, 6.4, 16.0 and $40 \mathrm{mg} / \mathrm{L}$, geometric mean exposure concentrations of $0.56,1.66,3.60$ and $8.25 \mathrm{mg} / \mathrm{L}$ were calculated. In terms of the control, the algal cell density increased from a nominal level of $1 \times 10^{4}$ cells $/ \mathrm{mL}$ at $0 \mathrm{~h}$ to a mean value of $9.433 \times 10^{5}$ cells $/ \mathrm{mL}$ at $72 \mathrm{~h}$, representing sufficient algal growth to pass the validity criteria of the assay. Microscopic evaluation of the treated algal cells showed thinner and smaller cells at the two highest test concentrations (3.60 and $8.25 \mathrm{mg} / \mathrm{L}$ ) relative to the control. No algal effects were observed at the two lowest test concentrations.

\section{Activated sludge}

The validity criteria of a respiration rate was met by all control test flasks (at least $20 \mathrm{mg}$ oxygen per one gram of activated sludge in an hour), with measured values ranging from 33.0 to $39.8 \mathrm{mg} \mathrm{O}_{2} / \mathrm{g} / \mathrm{h}$. The reference substance 3,5-DCP caused substantial inhibition of the respiration rate with a mean 3-h EC50 value estimated to be $2.6 \mathrm{mg} / \mathrm{L}$. The percent inhibition for 3,5-DCP at 3.2, 10, 32 and $100 \mathrm{mg} / \mathrm{L}$ were 53.9, 76.1, 90.2 and 93.3, respectively. This was within the expected range of $2-25 \mathrm{mg} / \mathrm{L}$, which indicated the sludge was responding accordingly and confirmed the viability of the sludge microflora [12]. The respiration rates in all the control flasks were within $15 \%$ of each other. Therefore, the mean respiration rate of the control flasks associated with the reference substance and the relevant test concentration flasks was used to calculate the percent inhibition. The respiration rate of the abiotic control was negligible throughout the study.

\section{Identification of point-of-departure values}

Fish

Point-of-departure (POD) levels (i.e., $\mathrm{LC}_{50}$, LOEC, NOEC) for the definitive fish study are noted in Fig. 2. The study concentrations noted for the fish are the nominal concentrations. As noted in "Fish" section, mortality was observed at the highest test concentration (i.e., $1 \mathrm{mg} / \mathrm{L}$ ). At the next lower concentration, $0.5 \mathrm{mg} / \mathrm{L}$, an increased respiration rate was observed but no mortality. For the next lower concentration, $0.25 \mathrm{mg} / \mathrm{L}$, no effects were observed. Based on these observations, the fish $96-\mathrm{h}$ LOEC and NOEC are 0.5 and $0.25 \mathrm{mg} / \mathrm{L}$, respectively. Due to the lack of fractional mortality, the $96-\mathrm{h} \mathrm{LC}_{50}$ was estimated using the arithmetic mean of the 0 and $100 \%$ mortality concentrations resulting in a value of $0.75 \mathrm{mg} / \mathrm{L}$ with $95 \%$ confidence intervals $(\mathrm{CI})$ of $0.5-1 \mathrm{mg} / \mathrm{L}$.

\section{Daphnia magna}

Effect levels for the definitive Daphnia study are noted in Fig. 2. The study concentrations noted for the Daphnia effective levels are the analytically confirmed test concentrations rather than nominal concentrations. The Daphnia 48 -h NOEC was $1.28 \mathrm{mg} / \mathrm{L}$ as all organisms appeared to be swimming normally at this concentration and no immobilization effects were observed. The lowest 48-h test concentration resulting in immobilization effects was $2.69 \mathrm{mg} / \mathrm{L}$ (i.e., LOEC of $2.69 \mathrm{mg} / \mathrm{L}$ ). The concentration resulting in $100 \%$ immobilization was $6.89 \mathrm{mg} / \mathrm{L}$ (i.e., 48-h $\mathrm{EC}_{100}$ of $\left.6.89 \mathrm{mg} / \mathrm{L}\right)$. The $48-\mathrm{h} \mathrm{EC}_{50}$ was calculated to be $3.05 \mathrm{mg} / \mathrm{L}$ (95 \% CI 2.57-3.92 mg/L) (Fig. 2).

\section{Algae}

Effects levels for the definitive algal study are noted in Fig. 2. No effects were observed over $72 \mathrm{~h}$ at 0.56 and $1.66 \mathrm{mg} / \mathrm{L}$ (i.e., 72-h NOEC of $1.66 \mathrm{mg} / \mathrm{L}$ ). Significant growth inhibition was observed over $72 \mathrm{~h}$ at $\geq 3.60 \mathrm{mg} / \mathrm{L}$ (i.e., 72-h LOEC of $3.60 \mathrm{mg} / \mathrm{L}$ ). The 72-h EC 50 (i.e., $\mathrm{EC}_{50}$ for growth) was estimated to be $5.46 \mathrm{mg} / \mathrm{L} \mathrm{(95 \%} \mathrm{CI} \mathrm{4.98-}$ $5.99 \mathrm{mg} / \mathrm{L}$ ) and $5.42 \mathrm{mg} / \mathrm{L}(95 \%$ CI $4.77-6.16 \mathrm{mg} / \mathrm{L}$ ) using the third and fourth highest test concentrations, respectively. The geometric mean of the $\mathrm{EC}_{\mathrm{r} 50}$ values is $5.44 \mathrm{mg} / \mathrm{L}$. The 72-h $\mathrm{EC}_{\mathrm{y} 50}$ (i.e., $\mathrm{EC}_{50}$ for yield) was estimated to be $2.79 \mathrm{mg} / \mathrm{L}$ (95\% CI 2.62-2.97 mg/L) and 2.35 (95\% CI 2.08-2.66 mg/L) using the third and fourth highest concentrations, respectively. The geometric mean of the $\mathrm{EC}_{\mathrm{y} 50}$ of values is $2.56 \mathrm{mg} / \mathrm{L}$.

\section{Activated sludge}

The NOEC and LOEC were determined to be 20 and $60 \mathrm{mg} / \mathrm{L}$, respectively. The $3-\mathrm{h} \mathrm{EC}_{20}, \mathrm{EC}_{50}$ and $\mathrm{EC}_{80}$ values were calculated to be $46 \mathrm{mg} / \mathrm{L}$ (95\% CI 37-73 mg/L), $216 \mathrm{mg} / \mathrm{L}$ (95 \% CI 187-252 mg/L) and $504 \mathrm{mg} / \mathrm{L} \mathrm{(95 \%}$ 


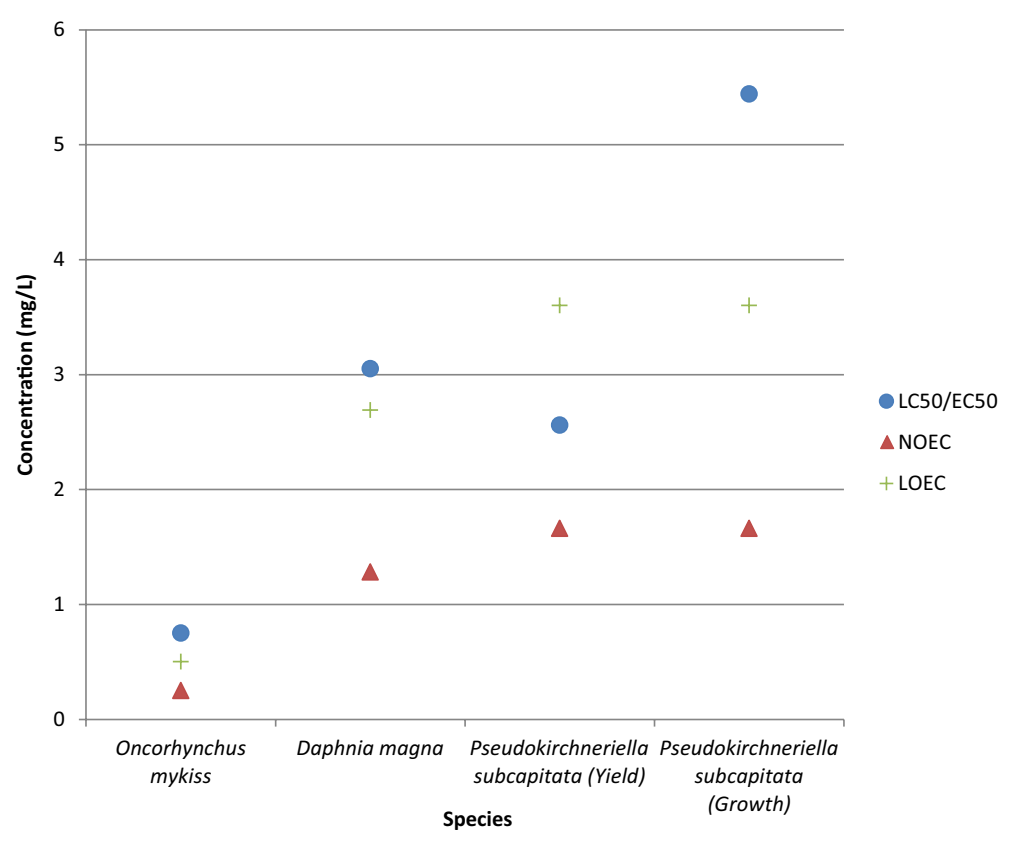

Fig. 2 PSOA point-of-departure concentrations for O. mykiss, D. magna and P. subcapitata

CI 480-525 mg/L), respectively. All POD values are based on nominal concentrations.

\section{Discussion}

PSOA was developed as a surfactant peracid to alleviate challenges with current peracid technology. Given its commercial applications, the primary disposal mode for PSOA is via industry wastewater effluent, which raises the importance of understanding whether the substances pose a risk to the aquatic environment. Evaluation of acute aquatic toxicity endpoints is a critical first step in evaluating the aquatic hazards of PSOA for risk assessment given its primary mode of disposal.

The aquatic toxicity studies described in this article were performed according to standard OECD test guidelines, where applicable. Given the reactivity of PSOA, significant effort was expended to confirm nominal test concentrations with analytical measurements, with the exception of the activated sludge assay. In reviewing the acute toxicity results, $\mathrm{LC}_{50}$ and $\mathrm{EC}_{50}$ values for fish, $D$. magna and algae ranged from 0.75 to $5.44 \mathrm{mg} / \mathrm{L}$, representing a relatively small range of less than an order of magnitude. However, the $\mathrm{EC}_{50}$ value calculated for sludge was appreciably higher at $216 \mathrm{mg} / \mathrm{L}$. It is unclear why the aquatic species were more sensitive to PSOA than the sludge microflora; however, the rapid reactivity and subsequent attenuation of PSOA once it comes into contact with organic matter may help explain this observation.
In terms of acute NOECs $(0.25-1.66 \mathrm{mg} / \mathrm{L})$ and LOECs (0.5-3.6 $\mathrm{mg} / \mathrm{L})$ for the aquatic organisms, a similar observation of the $\mathrm{LC}_{50} / \mathrm{EC}_{50}$ ratio occurred; the NOEC and LOEC ranges were less than an order of magnitude apart. In terms of activated sludge, the NOEC $(20 \mathrm{mg} / \mathrm{L})$ and LOEC $(60 \mathrm{mg} / \mathrm{L})$ values were higher than the corresponding values for the test aquatic species. The small ranges for the POD values for the aquatic species indicates that PSOA has a relatively steep dose-response curve and rapid transitions from non-toxic concentrations to toxic levels over a small concentration range.

The mode-of-action for PSOA is not known, but of its four primary structural elements (i.e., hydroperoxide structure, acid component, sulfonate moiety and monohydroxy structure), the hydroperoxide structure is generally considered to be the defining component of the toxicity of PSOA [13]. In assessing the acute aquatic and microbial toxicity hazards of PSOA, insight can be garnered from evaluating acute toxicity studies conducted with similar hydroperoxides. Peracetic acid (PAA, CASRN 79-21-0) and tert-butyl hydroperoxide (TBHP, CASRN 75-91-2) are two representative hydroperoxides that can be used for comparison purposes (results shown in Table 1). From the table, it appears that PSOA has similar potency to PAA in terms of acute toxicity to $O$. mykiss but is slightly less potent to D. magna and $P$. subcapitata than PAA and appreciably less toxic to microorganisms. In comparison to TBHP, PSOA displayed 
Table 1 Comparison of acute aquatic toxicity and microbial toxicity point-of-departure values for PSOA, PAA and TBHP

\begin{tabular}{|c|c|c|c|c|c|c|}
\hline \multirow[t]{3}{*}{ Species } & \multicolumn{6}{|c|}{ Peracid chemistry } \\
\hline & \multicolumn{2}{|l|}{ PSOA } & \multicolumn{2}{|l|}{$\mathrm{PAA}^{\mathrm{a}}$} & \multicolumn{2}{|l|}{$\mathrm{TBHP}^{\mathbf{b}}$} \\
\hline & NOEC (mg/L) & $\mathrm{LC}_{50} / \mathrm{EC}_{50}(\mathrm{mg} / \mathrm{L})$ & NOEC (mg/L) & $\mathrm{LC}_{50} / \mathrm{EC}_{50}(\mathrm{mg} / \mathrm{L})$ & NOEC (mg/L) & $\mathrm{LC}_{50} / \mathrm{EC}_{50}(\mathrm{mg} / \mathrm{L})$ \\
\hline Oncorhynchus mykiss (96-h) & $0.25(N=1)$ & $0.75(N=1)$ & $0.16-1.5(N=4)$ & $0.91-2(N=4)$ & $29.8(N=1)$ & $29.61-56.88(N=2)$ \\
\hline Daphnia magna (48-h) & $1.28(N=1)$ & $3.05(N=1)$ & $0.035-<1(N=7)$ & $0.035-1.1(N=7)$ & $7(N=1)$ & $14.1(N=1)$ \\
\hline $\begin{array}{l}\text { Pseudokirchneriella subcapitata (72-h } \\
\text { growth rate) }\end{array}$ & $1.66(N=1)$ & $5.44(N=1)$ & $0.084(N=1)$ & $0.035-0.86(N=2)$ & $0.22(N=1)$ & $1.5(N=1)$ \\
\hline $\begin{array}{l}\text { Pseudokirchneriella subcapitata (72-h } \\
\text { yield) }\end{array}$ & $1.66(N=1)$ & $2.56(N=1)$ & $<1(N=1)$ & $<1(N=1)$ & $0.22(N=1)$ & $0.8(N=1)$ \\
\hline Activated sludge (3-h) & $20(N=1)$ & $216(N=1)$ & $16.7(N=1)$ & $5.1-38.6(N=2)$ & Not reported & $17(N=1)^{c}$ \\
\hline
\end{tabular}

a Referenced in OECD [11]

b Referenced in ECHA [6]

c 30 -min value rather than $3 \mathrm{~h}$

greater toxicity to O. mykiss and D. magna but lower toxicity to P. subcapitata and sludge microorganisms. These comparisons are limited given the paucity of studies conducted for PSOA and TBHP, particularly relative to PAA. It is noted that much of the available aquatic information for peracids are based on industry-sponsored studies summarized in publicly available databases. There is relatively little published information for peracid in the peerreviewed scientific literature. Therefore, a discussion on species sensitivity would be based on speculation regarding toxicity such as metabolic capacity of certain aquatic species that allow the bioactivation of PSOA resulting in, e.g., oxidative stress. Further the discussion above about the mode-of-action shows that structural similar chemicals show different species sensitivity regarding toxicity.

The data for $O$. mykiss were used to derive an aquatic health benchmark for PSOA for use in a risk assessment given that this species displayed the greatest sensitivity to PSOA. The $96-\mathrm{h} \mathrm{LC}_{50}$ of $0.75 \mathrm{mg} / \mathrm{L}$ for $O$. mykiss was used to derive an aquatic predicted no effect concentration (PNEC) for PSOA. The activated sludge 3-h NOEC of $20 \mathrm{mg} / \mathrm{L}$ was used to derive a health benchmark for sewage treatment plants. Table 2 provides a description of the aquatic and sewage treatment PNEC values for PSOA.

As noted earlier, the disposal of PSOA via industry wastewater effluent requires identification of aquatic hazards of this chemical. The acute aquatic and microbial toxicity testing of PSOA enables identification of these hazards, as well as derivation of various environmental health benchmarks (i.e., PNECs). However, another critical facet to assessing the overall risk of PSOA to aquatic environments is to consider its environmental fate and transport.

The stability of PSOA in aqueous environments under environmentally relevant $\mathrm{pH}$ values has been assessed following OECD Test Guideline 111 [2]. At $\mathrm{pH}$ levels of 4, 7 and 9, PSOA had hydrolyzed $>10 \%$ after 5 days with an estimated half-life of $<1$ year [2]. Based on these results, PSOA is considered hydrolytically unstable at environmentally relevant $\mathrm{pH}$ values. Experience with PSOA indicates that its stability in water is influenced by its aqueous concentration, with low ppm levels of PSOA showing less stability than higher concentrations (data not shown). This is important considering that in commercial applications of PSOA, the chemical is diluted prior to application and wastewater effluent containing PSOA is likely to be mixed with other facility wastewater lacking PSOA, further diluting the overall PSOA concentration prior to discharge and potentially accelerating chemical hydrolysis. Therefore, PSOA is not expected to persist in the environment.

Another important consideration is the microbial degradation potential of PSOA in aqueous environments. In an assessment following OECD Test Guideline 301B, PSOA biodegraded $56 \%$ after 28 days with $40 \%$ biodegradation observed by the Day 10 observation point (LAUS [8]. Though PSOA did not meet the OECD criteria for consideration as a "readily biodegradable" substance under the conditions tested, it did demonstrate appreciable aqueous biodegradability.

To gauge the hydrophilic nature of PSOA, EPI Suite software [KOWWIN Program (v1.68)] was used to estimate the Log Kow values for two of the primary components of PSOA, 10-hydroxy-9-sulfooctadecaneperoxoic acid and 10-hydroxy-9-sulfooctadecanoic acid [16]. Based on this work, a representative Log Kow of 3.12 was identified. The adsorption coefficient (Log Koc) can be used to estimate PSOA's ability to bind to suspended sediment in water. Testing conducted in accordance with OECD Test Guidelines 121 identified Koc values ranging from 0 to 190,546 ( $\log$ Koc of un-retained to 5.28) 
Table 2 Aquatic and sewage treatment plant PNEC for PSOA

\begin{tabular}{|c|c|c|}
\hline Environmental compartment & PNEC (mg/L) & Remarks and justification \\
\hline Freshwater_PNEC aqua (freshwater) & $0.00075^{\mathrm{a}}$ & $\begin{array}{l}\text { Assessment factor: } 1000 \\
\text { PNEC aqua (freshwater) equals lowest short-term LC50 value of } 0.75 \mathrm{mg} / \mathrm{L} \\
\quad \text { (fish) divided by assessment factor of } 1000\end{array}$ \\
\hline Marine water_-PNEC aqua (marine water) & $0.000075^{\mathrm{a}}$ & $\begin{array}{l}\text { Assessment factor: 10,000 } \\
\text { PNEC aqua (marine water) equals lowest short-term LC50 value of } 0.75 \text { mg/L } \\
\text { (fish) divided by assessment factor of 10,000 }\end{array}$ \\
\hline $\begin{array}{l}\text { Intermittent releases to water_-PNEC aqua } \\
\text { (intermittent releases) }\end{array}$ & $0.0075^{\mathrm{a}}$ & $\begin{array}{l}\text { Assessment factor: } 100 \\
\text { PNEC aqua (intermittent releases) equals lowest short-term LC50 value of } \\
0.75 \mathrm{mg} / \mathrm{L} \text { (fish) divided by assessment factor of } 100\end{array}$ \\
\hline Sewage treatment plant_—PNEC (STP) & 2 & $\begin{array}{l}\text { Assessment factor: } 10 \\
\text { PNEC STP equals } 3 \mathrm{~h} \text { NOEC of } 20 \mathrm{mg} / \mathrm{L} \text { divided by assessment factor of } 10\end{array}$ \\
\hline
\end{tabular}

a PSOA is not anticipated to be hydrolytically stable at these environmental concentrations

[1]. To identify a representative value in this range, a Koc weighted average based on the percent peak area of the test solutions was calculated to be 1.06, resulting in a Log Koc estimate of 0.024 . This representative value indicates a relatively low sediment binding potential overall for the PSOA mixture; however, select minor fractions of the PSOA mixture may readily bind sediment.

Based on the laboratory tests conducted for PSOA, it is suggested that the environmental aqueous fate of this substance would be to exist largely unbound in the water column with hydrolytic and biological factors degrading the chemical and limiting its availability to aquatic organisms. The rate of degradation may vary appreciably depending on the initial concentration of PSOA in the water column, and for some fractions of this mixture, persistence in the aqueous environment is possible. Additionally, a minor fraction of the PSOA mixture does displays appreciable sediment affinity which is anticipated to attenuate its toxicity and could increase its persistence in the aqueous environment.

As part of the requirements under the Registration, Evaluation, Authorization and Restriction of Chemicals $(\mathrm{REACH})$, an environmental risk assessment was conducted using EUSES software to determine if the proposed uses of PSOA posed an unacceptable risk to aqueous environments. All risk characterization ratios (RCRs), which are ratios of the PNEC to the estimated environmental concentration (i.e., estimated environmental concentration/PNEC), were $<0.01$, indicating no unacceptable risk to the environment [4]. Therefore, despite notable acute aquatic hazards for PSOA when considering the acute toxicity values, no unacceptable risk to the aqueous environment is anticipated based on its use and other factors. This aligns with the qualitative assessment that PSOA in industry wastewater effluent would be further treated and diluted via a municipal waste water treatment facility prior to release to aquatic environments. Such treatment and dilution is anticipated to render PSOA below concentrations that pose a risk to native fauna or flora.

\section{Conclusion}

PSOA is a novel surfactant peracid whose commercial use will result in disposal via industrial wastewater effluent. Given this manner of disposal, it is important to understand the aquatic hazards of the chemical to better assess the risk posed to aqueous environments. Laboratory testing of PSOA for representative freshwater fish, invertebrate and algal species displays a degree of toxicity that appears to align with other peracid chemistries, such as peracetic acid. However, PSOA displayed appreciably lower microbial toxicity in activated sludge relative to other peracids. Despite the relatively high acute aquatic hazards for PSOA, environmental modeling suggests the overall risk of PSOA to aqueous environments is low based on its anticipated uses. Such a conclusion aligns with the significant processing of industrial wastewater by municipal wastewater treatment facilities prior to release to the environment.

\section{Authors' contributions}

This paper is part of a global registration project of PSOA manufactured by Ecolab. All authors have made substantial contributions to conception and design, acquisition of data, analysis, discussion and interpretation of data. They have been involved in drafting the manuscript or revising it critically for important intellectual content; and they have given final approval of the version to be published. BP contributed authoring the "Methods" section of the paper, as well as reviewing the Introduction, Results and Discussion. JC contributed authoring the "Results" section and reviewed the "Background" and "Methods" sections. MO wrote the introduction, assisted with the "Results" section, and peer reviewed the entire article. NP contributed authoring and reviewing to all sections of the paper. SS contributed authoring and reviewing to all sections of the paper. He was the study monitor and managed the authoring team.

\section{Authors' information}

All authors are working at Regulatory Affairs and are member of Ecolab's Global Corporate Toxicology Team. BP is Associate Regulatory Specialist working on hazard communication. JC (M.S.) is Regulatory Specialist 1 working on 
hazard communication. MO (B.A. in Biology, Society and Environment, Associate) is Regulatory Specialist working on hazard communication. NP (M.S., DABT) is Principal Regulatory Specialist working as subject matter expert in toxicology. SS (Food Chemist, Dr. rer. nat.) is working as subject matter expert in food and environmental safety. He is member of the GDCh and is doing the post-graduate study to become a certified ecotoxicologists established by the SETAC-GLB/GDCh.

\section{Author details}

${ }^{1}$ Ecolab, Monheim, Germany. ${ }^{2}$ Ecolab, St. Paul, MN, USA. ${ }^{3}$ Ecolab, Naperville, IL, USA.

\section{Acknowledgements}

The authors acknowledge Charles River Laboratories for conducting the acute fish study, Toxicoop-ZRT for conducting the acute D. magna and algae studies, and LAUS GmbH for conducting the activated sludge study. The authors also acknowledge Kathryn Sande for her input during the development of the manuscript. This study is based on regulatory scientific work which is an inherent part of the post-graduate study for certified ecotoxicologists, established by the SETAC-GLB/GDCh in 2005. The corresponding author wants to thank SETAC-GLB/GDCh for providing the opportunity to receive advanced training in ecotoxicology.

\section{Compliance with ethical guidelines}

\section{Competing interests}

The authors are employed by Ecolab. PSOA is manufactured by Ecolab. Therefore, none of the authors have competing interests.

Received: 21 June 2015 Accepted: 23 September 2015

Published online: 30 September 2015

\section{References}

1. Charles River Laboratories (2011) Product chemistry of PSOA: determination of adsorption coefficient. Study No. 219311. Edinburgh, United Kingdom

2. Charles River Laboratories (2012). Product chemistry of PSOA: determination of hydrolysis as a function of pH. Study No. 219295. Edinburgh, United Kingdom
3. Charles River Laboratories (2012b) Validation of methodologies for the formulation and analysis of PSOA in tap water. Study No. 428044. Edinburgh, United Kingdom

4. Ecolab (2013) Chemical safety report, reaction product of sulfonated oleic acid potassium salts, hydrogen peroxide and sulfuric acid. CAS No. 1315321-94-8

5. European Chemicals Agency (ECHA) (2011) Guidance for identification and naming of substances under REACH and CLP, ECHA-11-G-10-EN

6. European Chemicals Agency (ECHA) (2013) Registered substances, tertbutyl hydroperoxide. CAS No. 75-91-2

7. Hilgren J (2014) Microsoft Power Point Presentation —PSOA: new data supporting inert petition 26 February 2014

8. LAUS GmbH (2011) Determination of the aerobe ready biodegradability of PSOA (peroxy sulfonated oleic acids) in the $\mathrm{CO}_{2}$ evolution test following OECD 301B resp. EUC.4.C. Study No. 11051701G605. Kirrweiler, Germany

9. Organization of Economic Co-operation and Development (OECD) (1992) Fish, acute toxicity test. Test Number: 203. OECD guidelines for the testing of chemicals, Section 2, OECD Publishing. doi:10.1787/9789264069961-en

10. Organization of Economic Co-operation and Development (OECD) (2004) Daphnia sp. acute immobilisation test. Test Number: 202. OECD guidelines for the testing of chemicals, Section 2, OECD Publishing. doi:10.1787/9789264069947-en

11. Organization of Economic Co-operation and Development (OECD) (2008) Screening information dataset (SIDS) dossier, peracetic acid. CAS No. 79-21-0

12. Organization of Economic Co-operation and Development (OECD) (2010) Activated sludge, respiration inhibition test (carbon and ammonium oxidation). Test Number: 209. OECD guidelines for the testing of chemicals, Section 2, OECD Publishing. doi:10.1787/9789264070080-en

13. Pechacek N, Laidlaw K, Clubb S, Aulmann W, Osorio M, Caudill J (2013) Toxicological evaluation of peroxy sulfonated oleic acid (PSOA) in subacute and developmental toxicity studies. Food Chem Toxicol 62:436-447

14. Sanchez M, Meyers TN (1996) Kirk-Othmer Encyclopedia of Chemical Technology, 4th edn. vol 18. Wiley, Inc., pp 230-310

15. TOXI-COOP_ZRT (2011) Determination of water solubility of PSOA. Study No. 675-107-2971, Balatonfüred, Hungary

16. TOXI_COOP_ZRT (2011) Determination of the partition coefficient of PSOA (peroxy sulfonated oleic acids). Study No. 675.194.2970. Balatonfüred, Hungary

\section{Submit your manuscript to a SpringerOpen ${ }^{\odot}$ journal and benefit from:}

- Convenient online submission

- Rigorous peer review

- Immediate publication on acceptance

- Open access: articles freely available online

- High visibility within the field

- Retaining the copyright to your article

Submit your next manuscript at $\boldsymbol{~ s p r i n g e r o p e n . c o m ~}$ 